\title{
Genetic Basis for Productivity in Anthurium andraeanum Hort.
}

\author{
Winston Elibox and Pathmanathan Umaharan ${ }^{1}$ \\ Department of Life Sciences, Faculty of Science and Technology, The University \\ of the West Indies, St. Augustine Campus, College Road, St. Augustine, Republic \\ of Trinidad and Tobago
}

Additional index words. coefficient of variation, hybridization, non-additive genetic effects, parent-offspring regression, recurrent mass selection, transgressive segregates

\begin{abstract}
Anthurium andraeanum Hort. is an important tropical ornamental crop regarded as second only to orchids in its commercial importance. The genetic basis for productivity in anthurium was studied using parent-offspring regression analysis. Sixteen parental genotypes (4 years old) and 14 biparental progeny families (60 plants each, 4 years old) derived from the parents were used in the study. Yield expressed as number of cut flowers per plant per year (CFPY) was significant both between parental genotypes $(P<0.001)$ and between progeny families $(P<0.05)$. Mean CFPY of the parent genotypes was normally distributed and ranged from 4.8 in 'Local Mina Red' to 9.8 in 'Kalapana' with a mean of 7.5. CFPY in Year 1 was strongly correlated to that in Year 2 (Pearson's $r=0.96$; Spearman's $r=0.93$ ) and the broad sense heritability $\left(\mathrm{H}^{2}\right)$ was high $(87.6 \%)$ under controlled shadehouse conditions. CFPY in the progeny families varied from four to 14 with progeny means ranging from 5.7 in 'Honduras/Local Mina Red' to 7.2 in 'Mirjam/Kalapana'. Progeny of seven and 10 crosses possessed mean CFPY greater than that of the more productive parent and the midparent values, respectively. The frequency distribution for productivity of the 840 progeny plants was skewed to the right with a modal class of six to seven. The correlation coefficient between progeny CFPY and midparent CFPY was large and significant $(r=0.90, P<0.001)$. The regression of mean progeny CFPY on mean midparental CFPY was strong $\left(y=0.51 x+2.56 ; R^{2}=\right.$ $0.81)$ with an estimated narrow sense heritability $\left(h^{2}\right)$ of $51.0 \%$. A breeding strategy for improving per plant productivity based on the results is discussed.
\end{abstract}

Anthurium is a neotropical genus (Croat, 1988) belonging to the monocotyledonous family Araceae, which includes more than 100 genera and $\approx 1500$ species (Croat, 1988; Higaki et al., 1994). Native species of Anthurium occur from Mexico through Central America and the Caribbean to Brazil (Kamemoto and Kuehnle, 1996). Cultivated anthuriums belong to two (Calomystrium and Porphyrochitonium) of 18 sections outlined by Kamemoto and Kuehnle (1996). Interspecific hybridization between species of Anthurium belonging to the section Calomystrium has resulted in an Anthurium species complex, referred to as Anthurium andraeanum Hort.

Anthurium is cultivated primarily for its showy cut flowers and glossy leaves that are exported or sold locally. The important horticultural features of the cut flower are its color, size, texture, shape and showiness of the spathe, spadix length and carriage, straightness of the peduncle and peduncle length, overall symmetry of the cut flower, and productivity (Kamemoto et al., 1986; Kamemoto and Kuehnle, 1996). Productivity is particularly important because it determines the profitability of an anthurium farm and hence is an important selection criterion in anthurium

Received for publication 10 Jan. 2014. Accepted for publication 22 May 2014.

${ }^{1}$ To whom reprint requests should be addressed; e-mail Pathmanathan.Umaharan@sta.uwi.edu. breeding (Elibox and Umaharan, 2012; van Herk et al., 1998). On average, a single growing axis produces only five or six cut flowers per year, and consequently a difference of one cut flower per plant per year may translate into large economic differences on a hectare basis (Kamemoto and Kuehnle, 1996). Generally, in the Caribbean (Elibox, 2005; Elibox and Umaharan, 2012) and worldwide (Kamemoto and Kuehnle, 1996; Kamemoto and Nakasone, 1963), an average of six cut flowers per plant per year is considered critical for a profitable anthurium industry.

Although Trinidad and Tobago experiences two seasons (a dry and a wet season) per year, it has been found that seasonal difference in anthurium genotype productivity under shadehouse conditions, where shade regime, potting medium and watering, and fertilization regimes were controlled, was not significant (Campbell, 2006). Furthermore, anthurium productivity does not peak until after 3 years of field planting for either tissuecultured plants or seedlings (Holder, 2005) and remains stable for at least 5 years thereafter. There has been very little progress with regard to productivity improvement in anthurium worldwide because there is no information on the heritability of productivity or its genetic basis, both of which are required in developing a breeding strategy to improve productivity in anthurium. The objective of this research is to determine the genetic basis for productivity in Anthurium andraeanum Hort.
Location. The study was conducted in a commercial anthurium farm, Kairi Blooms Ltd., situated in Arima, Trinidad and Tobago. The location experiences two seasons: a dry season (January to May) and a wet season (June to December). The average relative humidity, temperature, and light intensity at the location are $83 \%, 27.7^{\circ} \mathrm{C}$, and $57 \mu \mathrm{mol} \cdot \mathrm{m}^{-2} \cdot \mathrm{s}^{-1}$, respectively.

Cultural conditions. The study was conducted in a shadehouse covered with clear plastic on top and Saran netting ( $75 \%$ shade) below. The plants were grown in plastic pots (21 cm diameter and $22 \mathrm{~cm}$ deep) containing peatmoss (Premier Horticulture Ltd., Quebec, Canada) at the center and coconut husk around. The plants were hand-watered once daily on an individual plant basis to prevent splashing and fertilized (1.5 g) on a monthly basis with either triple superphosphate (Chemos GmBH, Regenstauf, Germany) or $12 \mathrm{~N}$ 11P-13K (Norsk Hydro Olje AB, NYBRO, Sweden). The $\mathrm{pH}$ of the growing medium was maintained at 5.5 by continuous monitoring and applying calcium carbonate (limestone; TRINCARB, Trinidad) as necessary. The nematicide Temik (Aldicarb, Shandong, China) was applied once to prevent nematode infestation.

Measurements in the parental genotypes (Expt. 1). Four-year-old plants of 16 anthurium genotypes (Table 1) representing the range of variation for productivity were evaluated for productivity over a 2-year period (Kamemoto and Nakasone, 1963) in the shadehouse. The plants were originally derived from tissue culture. The experiment was set out in a randomized complete block design with three replications and with five plants per replicate. The plants were arranged on a plant stand $(0.61 \mathrm{~m}$ high) made of wire mesh and spaced out, $60 \mathrm{~cm} \times 60 \mathrm{~cm}$.

Three-quarter ripe cut flowers (true flowers are open along three-fourths of the length of the spadix) were harvested on a daily basis from Monday to Friday between 0700 and 1100 HR over 2 years. Each plant was tagged with a white plastic tag that was ticked using a permanent marker every time a new cut flower was harvested. From the cut flowers harvested from each replicate, average number of CFPY for each genotype was calculated for each year separately.

Hybridization and aftercare of progeny. Fourteen random crosses were made involving the 16 parental genotypes without reciprocals. Crossing was as described by Higaki et al. (1994). Six months after pollination, the ripe berries from each cross were collected, seeds squeezed out, and planted in a labeled (name of cross, sowing date) seedling tray containing peatmoss in a nursery shadehouse ( $75 \%$ shade). The seedlings were watered every day for $10 \mathrm{~s}$ at 15 -min intervals between 0900 and $1600 \mathrm{HR}$ using a mist irrigation system. A $20 \mathrm{~N}-20 \mathrm{P}-20 \mathrm{~K}$ foliar fertilizer, Nutrex (Marman USA Inc., Tampa, FL), was spray-applied twice a week at a concentration of $1.5 \mathrm{~g} \cdot \mathrm{L}^{-1}$ of water, and micronutrients 
Table 1. Productivity data, measured as number of cut flowers per plant per year $(\mathrm{CFPY})$ and $\mathrm{CV}_{\text {within }}$ obtained for 16 genotypes of Anthurium andraeanum Hort. in Expt. 1 and Expt. 2.

\begin{tabular}{|c|c|c|c|c|}
\hline \multirow[b]{3}{*}{ Genotype } & \multicolumn{4}{|c|}{ Productivity (number of CFPY) } \\
\hline & \multicolumn{2}{|c|}{ Expt. 1} & \multicolumn{2}{|c|}{ Expt. 2} \\
\hline & Mean & $\mathrm{CV}$ within percent & Mean & $\mathrm{CV}$ within percent \\
\hline Acropolis & 5.8 & 9.1 & 6.0 & 11.3 \\
\hline Champagne & 7.2 & 7.3 & 7.8 & 8.4 \\
\hline Cross 3962 & 6.3 & 6.2 & 6.0 & 7.6 \\
\hline Cuba & 8.5 & 6.9 & 8.9 & 5.8 \\
\hline Hawaii & 8.5 & 8.4 & 8.1 & 9.3 \\
\hline Honduras & 8.7 & 8.8 & 9.1 & 11.0 \\
\hline Ibara & 6.2 & 9.4 & 6.6 & 7.5 \\
\hline Kalapana & 9.8 & 7.4 & 10.0 & 9.6 \\
\hline Local Mina Red & 4.8 & 8.2 & 4.5 & 7.9 \\
\hline Local Orange & 7.0 & 9.3 & 7.4 & 9.5 \\
\hline Lydia & 8.8 & 11.3 & 9.1 & 9.8 \\
\hline Mirjam & 9.2 & 11.1 & 8.8 & 10.5 \\
\hline Pierrot & 7.0 & 11.3 & 7.5 & 12.2 \\
\hline Senator & 8.2 & 8.6 & 7.1 & 8.6 \\
\hline Venus & 7.4 & 10.8 & 7.6 & 11.7 \\
\hline Victoria & 7.1 & 7.4 & 6.5 & 9.5 \\
\hline Significance $(P<)$ & 0.001 & - & 0.001 & - \\
\hline Mean & 7.5 & - & 7.6 & - \\
\hline SEM & 0.32 & - & 0.50 & - \\
\hline Least significant difference & 0.77 & - & 1.20 & - \\
\hline $\mathrm{CV}$ within percent & 8.8 & - & 9.4 & - \\
\hline Genotypic CV \% & 18.2 & - & 18.9 & - \\
\hline
\end{tabular}

(Biolchim S.p.A, Italy) were applied by foliar application as necessary at a rate of $9 \mathrm{~mL} \cdot \mathrm{L}^{-1}$ of water. Six months after germination, the seedlings were transplanted into labeled (cross, seedling number) $8 \mathrm{~cm} \times 8 \mathrm{~cm} \times 8$-cm pots and after another 1.5 years, they were transferred to larger pots $(21 \mathrm{~cm}$ diameter and $22 \mathrm{~cm}$ deep), like for the parental genotypes. The pots were clearly labeled and potted plants were grown for another 2 years before evaluating them for productivity.

Productivity of progeny generations (Expt. 2). Three replicates each of the parental genotypes (4 years old; five plants per replicate) and three replicates each of the 14 progeny families (4 years old) were arranged in a completely randomized design and evaluated for productivity over a period of 1 year as described before. Each replicate of the progeny family consisted of 20 randomly chosen progeny plants from the specific cross. The plants were spaced at $60 \mathrm{~cm} \times 60 \mathrm{~cm}$ as before. Aftercare and data collection were as described before.

Data analysis. With respect to Expt. 1, mean CFPY for each parent genotype per replicate (averaged over the 2 years) was calculated and a one-way analysis of variance (ANOVA) (NCSS, 2007) was performed to determine the significance of genotypic differences for CFPY. The $\mathrm{CV}$ for each genotype (NCSS, 2007), the average CV within genotypes $\left(\mathrm{CV}_{\text {within }}=\right.$ square root of the error mean square from ANOVA/grand mean), and the genotypic $\mathrm{CV}\left(\mathrm{CV}_{\text {between }}=\mathrm{SD}\right.$ between the mean of the genotypes/grand mean) were calculated. A two-way ANOVA was performed to determine the significance of year-to-year differences and the presence of genotype $\times$ year interactions. Pearson's product moment correlation and Spearman's rank correlation (NCSS, 2007) were performed to determine the association between parent genotype productivity over the 2 years. Shapiro-Wilk W test (NCSS, 2007) was conducted to test whether the distribution of mean CFPY for the parent genotypes over the 2 years was normally distributed. $\mathrm{H}^{2}$ for parent productivity was calculated according to Dabholkar (1999).

Correlation coefficients were calculated as before between mean genotype productivity in Expt. 1 and Expt. 2. In Expt. 2, mean CFPY and range for each progeny family were determined and the significance of differences between progeny family mean CFPY was tested using a one-way ANOVA (NCSS, 2007). Pearson's product moment correlation was carried out (NCSS, 2007) separately between mean progeny CFPY and that for male parent, female parent, and midparent values from Expt. 2. CV within each individual family and average CV within and between progeny families were determined as described before. The frequency histogram of productivity values for the 840 progeny plants evaluated was tested for normality using the Shapiro-Wilk W test (NCSS, 2007). The number of progeny plants that possessed productivity values larger than the more productive parent and midparent values were determined for each progeny family. Parentoffspring regressions were performed between progeny CFPY and those for male parent, female parent, and midparent values to determine the nature of the relationships; and the $\mathrm{h}^{2}$ for CFPY was estimated as the slope of the midparent-offspring regression according to Lush (1943).

\section{Results}

Productivity of the parent genotypes. There were significant differences in productivity
(CFPY) among the parent genotypes in Expt. $1(P<0.001)$ (Table 1). The year-toyear differences and genotype $\times$ year interactions were not significant $(P>0.05)$. The correlation between mean CFPY values between the 2 years was large (Pearson's $r=$ 0.96; Spearman's $r=0.93)$ and significant $(P<$ $0.001)$. Mean productivity values for the 16 parent genotypes ranged from 4.8 CFPY in 'Local Mina Red' to 9.8 CFPY in 'Kalapana' with a mean of 7.5 CFPY. The average $\mathrm{CV}$ within parent genotypes was small $(8.8 \%)$ but the genotypic $\mathrm{CV}$ was 2 -fold larger (18.2\%). The distribution of productivity values for the parental genotypes was normal (Shapiro-Wilk $\mathrm{W}$ test probability $=0.88, P>0.05$ ) with a high $\mathrm{H}^{2}(87.6 \%)$.

In Expt. 2, productivity of parents ranged from 4.5 CFPY in 'Local Mina Red' to 10 CFPY in 'Kalapana' with a mean of 7.6 CFPY. The $\mathrm{CV}$ between the parent genotypes $(18.9 \%)$ was 2 -fold larger than the average CV within genotypes $(9.4 \%)$. The correlation between mean parent genotype productivity in Expt. 1 and Expt. 2 (Table 1) was large (Pearson's $r=0.94$; Spearman's $r=0.91$ ) and significant $(P<0.001)$ and showed that productivity values for the parent genotypes were repeatable over 2 years.

Productivity of the progenies in the crosses. There were significant differences in productivity among the progeny families $(P<0.05)$. Family 'Mirjam/Kalapana' had the largest mean productivity value (7.2 CFPY) and 'Honduras/Local Mina Red' had the lowest CFPY (5.7) (Table 2). Progeny plants within 'Acropolis/Victoria' had the largest range in productivity (four to 14 CFPY) followed by 'Honduras/Cross 3962' (four to 12 CFPY). On the other end, four families had smaller ranges for CFPY ('Honduras/Local Mina Red', 'Champagne/Venus', 'Mirjam/Kalapana', and 'Senator/Hawaii').

The frequency distribution for progeny productivity values over all crosses was continuous and skewed to the right (Shapiro-Wilk test probability $=0.00 ; P<0.05)$, i.e., toward low productivity (Fig. 1) with the modal class between six and seven CFPY. Among the progeny families, there was evidence of better parent heterosis in seven $(50 \%)$ families ('Acropolis/Victoria', 'Acropolis/Cross 3962', 'Champagne/Ibara', 'Champagne/Venus', 'Honduras/Cross 3962', 'Local Orange/Cuba', and 'Pierrot/Local Orange'), but $\approx 71.4 \%$ of the progeny families showed midparent heterosis (Table 2).

Parent-offspring regression. Correlation between mean progeny productivity values and mean female parent productivity values was very small and not significant $(r=0.14$, $P>0.05)$, but the correlations between mean progeny productivity values and mean male parent productivity values $(r=0.79, P<0.01)$ and between mean progeny productivity values and midparent productivity values $(r=0.90, P<0.001)$ were significant. Regression of mean progeny productivity values against mean male parent productivity values was moderate $\left(R^{2}=0.63\right)$ and can be represented by the equation $\mathrm{y}=0.2219 \mathrm{x}+4.80$, whereas 
Table 2. Mean progeny productivity (number of cut flowers per plant per year $\pm \mathrm{SD}$ ), $\mathrm{CV}_{\text {within }}$ each family, range of productivity, and percentage of progeny plants with productivity larger than the more productive parent, midparent for 14 crosses of Anthurium andraeanum Hort. evaluated in Expt. 2.

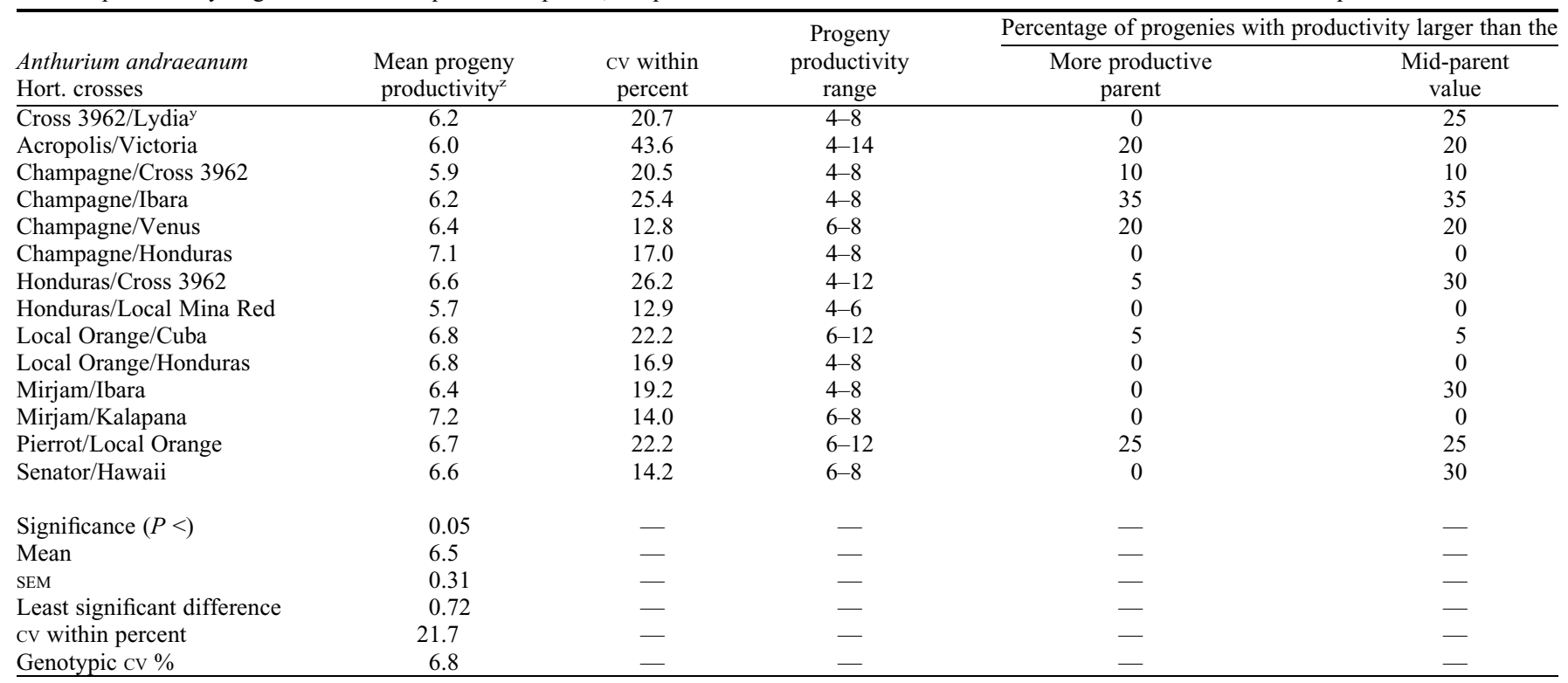

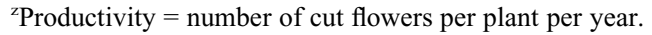

${ }^{\mathrm{y}}$ First parent is the female parent and the second parent is the male parent. Each progeny family comprised 60 plants.

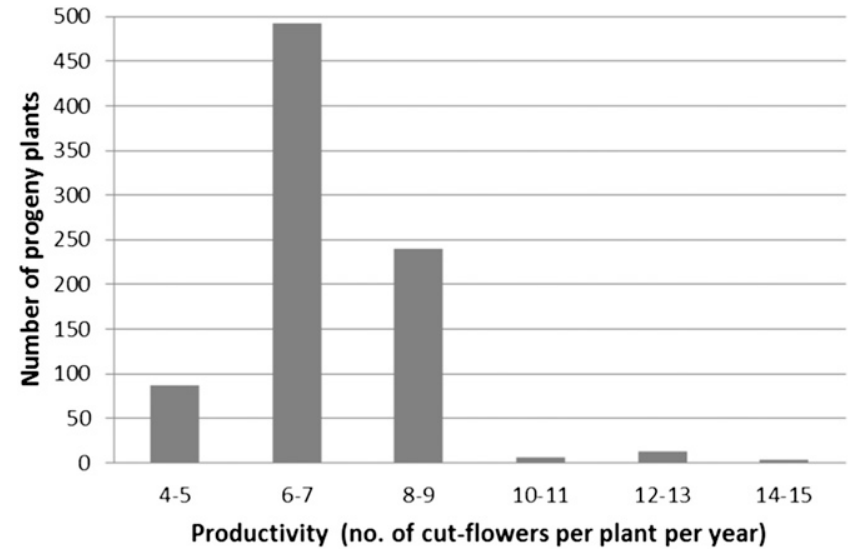

Fig. 1. Frequency distribution for productivity of 840 Anthurium andraeanum Hort. progeny plants derived from 14 crosses.

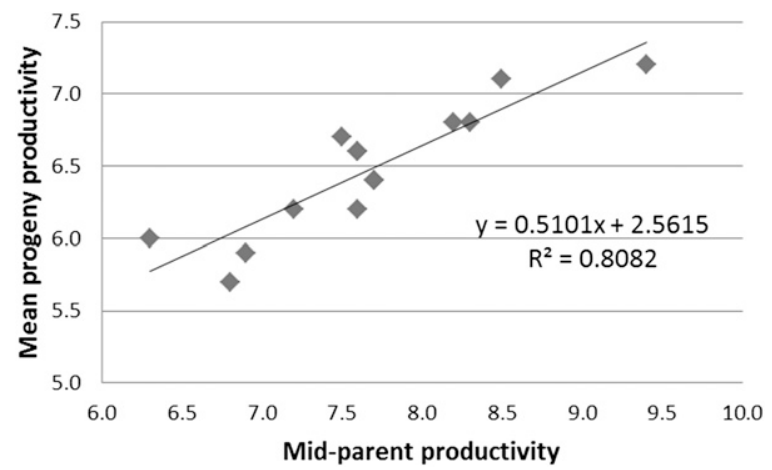

Fig. 2. Midparent-offspring regression for 14 crosses of $A$. andraeanum Hort. used in the productivity experiment.

regression of progeny mean productivity values on mean midparent productivity values (Fig. 2 ) was much stronger $\left(R^{2}=0.81\right)$ and can be represented by the equation: $\mathrm{y}=0.5101 \mathrm{x}+$
2.56. This strongly suggests that inheritance for productivity in anthurium is biparental with an estimated $\mathrm{h}^{2}$ (breeding value) of $51.0 \%$.
Discussion

Maintaining high productivity is essential for the commercial viability of the anthurium cut flower industry. Much of the work in the past (Campbell, 2006; Kobayashi et al., 2006; Nakasone and Kamemoto, 1962) has focused mainly on improving the agronomy toward improving productivity. This is the first study investigating the genetic variation and heritability of productivity in Anthurium with the view to improving productivity through breeding.

The study showed that there were differences between the parent genotypes and progenies with respect to productivity, which is in agreement with observations made in Hawaii by Kamemoto and Nakasone (1963). Furthermore, the productivity of the parent genotypes was consistent between the 2 years tested as evidenced by lack of year-to-year variation and lack of a significant genotype $\times$ year interaction based on ANOVA, a strong and significant positive correlation between mean genotypic values across trials, and a high $\mathrm{H}^{2}$ estimate of $87.6 \%$. Earlier work in Trinidad has also shown that under controlled shadehouse conditions, where the important environmental factors such as shade, growing medium, water, and nutrients are regulated, anthurium productivity is unaffected greatly by seasonal variation (Campbell, 2006). These results together suggest that under the uniform environmental conditions that prevail within the shadehouse setting, productivity levels can be ascertained with minimal environmental influences.

The frequency distribution for parent genotype productivity was found to be normal in this study with only 'Local Mina Red' possessing productivity values (mean of 4.7) below the accepted level of six to seven cut flowers per plant per year that is required for 
commercial success (Kamemoto and Kuehnle, 1996). The superiority of performance of parents used in this study may be because they were selected from commercially successful genotypes grown locally. The small $\mathrm{CV}$ within parental genotypes of $8.8 \%$ and 9.4\%, respectively, for Expt. 1 and Expt. 2 suggests that productivity was consistent among the clonal propagules of each genotype. The genotypic CV was 2-fold larger, suggesting that there exists a wide variation in productivity among locally adapted anthurium genotypes grown in Trinidad, which augurs well for future breeding efforts to improve productivity. A previous study (Elibox and Umaharan, 2012) reported that productivity was not associated with any other horticulturally important traits of anthurium and hence can be improved without affecting any other trait.

Mean productivity of progeny families across all crosses ranged from four to 14 cut flowers per plant per year. The $\mathrm{CV}_{\text {within }}$ progeny families was 3-fold that of $\mathrm{CV}_{\text {between }}$ families indicating that considerable variation was created through hybridization. This was especially evident in the cross 'Acropolis/Victoria', which had a within family CV of 43.6\%.

The frequency distribution of progeny productivity showed a skewed distribution with a mode of six to seven CFPY, which was just about the average required for a farm to be commercially viable (Elibox and Umaharan, 2012; Kamemoto and Kuehnle, 1996). The lack of transgressive segregation in four (28.6\%) crosses viz. 'Champagne/Honduras', 'Honduras/Local Mina Red', 'Local Orange/ Honduras', 'Mirjam/Kalapana' (Table 2), and the observation of transgressive segregation in 10 crosses $(71.4 \%)$ suggest that both nonadditive genetic effects (dominance and epistasis) and additive genetic effects (Falconer, 1981; Simmonds, 1979) are important in the inheritance of productivity in anthurium. The observation of better parent heterosis in only $50.0 \%$ of the families suggests that careful selection of parent combinations would be important in anthurium breeding to improve productivity. Generally, better parent heterosis (Kearsey and Pooni, 1996) is the most useful because it results in progeny plants that can markedly increase the number of CFPY. An increase of one cut flower per plant per year translates into a significant economic benefit to the farmer, because anthurium is cultivated at high plant densities (Kamemoto and Kuehnle, 1996). Although seven crosses $(50 \%)$ did not possess any better parent heterosis, the other seven crosses showed better parent heterosis ranging from $8.3 \%$ to $58.3 \%$ of the progenies (Table 2).

The $\mathrm{h}^{2}$ (the proportion of the phenotypic variability that is the result of the additive genetic effects) for productivity was moderate $(51 \%)$. The moderate $h^{2}$ and relatively high $\mathrm{H}^{2}$ (the proportion of the phenotypic variability that is the result of the genetic variation) of $87.6 \%$ suggests an important role for non-additive genetic effects (accounting for $36.6 \%$ of the phenotypic variability) in the inheritance of productivity (Simmonds, 1979).
The continuous but skewed distribution for progeny productivity also suggests that inheritance of productivity is polygenic (Falconer, 1981; Mather, 1943) with a moderate nonadditive component. Productivity has been shown to be polygenically determined in ornamentals such as gerbera (Harding et al., 1981) and sunflower (Leon et al., 2001). Anthurium plants produce one cut flower per leaf axil during the sympodial phase of growth (Dai and Paull, 1990; Dufour and Guerin, 2003; Kamemoto and Nakasone, 1963), and hence productivity is affected by genotype vigor (rate of leaf production), which affects it production potential. Furthermore, the productivity of anthurium plants is affected by light intensity (Henny et al., 1991), temperature, insects, diseases, water, and nutrition (Kamemoto and Kuehnle, 1996). Therefore, superior producing hybrids must be grown under the conditions that they were selected for to realize their full genetic potential.

We suggest that the lack of progress in breeding for increased productivity in anthurium may be attributed to variable field conditions in which selection was carried out and the moderate $h^{2}$ estimates obtained for productivity even under controlled environmental conditions such as those in this study. First, the study shows that under controlled shadehouse conditions such as those used in this study, the environmental effects can be minimized and repeatable results can be obtained. Second, understanding the genetic basis for productivity allows the breeder to use modifications to the selection strategy, which can greatly improve genetic gain. The moderate $\mathrm{h}^{2}$ for productivity suggests that breeding for high productivity may require progeny testing before selecting the parents. As was evident in this study, the superior parents did not necessarily provide the most productive families or the largest better parent heterosis. Progeny testing, however, will increase the cost of breeding. Alternatively, molecular markers that correlate with productivity can be researched and marker-assisted selection (Han et al., 2002; Mohan et al., 1997) can be practiced on the seedlings to determine the progeny plants that possess the quantitative trait loci for high productivity. This method has the ability to reduce the length and cost of breeding and quickly accumulate genes for productivity.

We also suggest a clonal breeding program with recurrent mass selection or marker-assisted selection be instituted to improve Anthurium. In this method, a large number of parents will be crossed and evaluated for progeny family performance and the top performing progeny from the best families will be clonally multiplied and distributed to anthurium growers. Based on the farmer testing, the top contenders could be used as parents in the second breeding cycle. Over several cycles, important genes for productivity will be accumulated.

Twenty-one progeny plants of the 840 evaluated possessed productivity values of 11 or greater. Such high productivity levels have never been observed in anthurium genotypes grown in Trinidad. The results suggest that anthurium breeding for productivity has the potential to double the yield per unit area of cultivation. Although not shown, some of the progeny plants possessed novel spathe colors that have never been reported before in anthurium, but the spathe sizes and shapes were in the range reported by Elibox and Umaharan (2012).

In summary, the study shows considerable variability for productivity in Anthurium among genotypes and progenies derived from crosses between them in Trinidad that augurs well for breeding. The high level of repeatability for productivity and the lack of genotype $\times$ environmental influences under shadehouse conditions suggest that significant improvements in productivity through selection can be obtained under this environment. All crosses produce some progenies with productivity of at least six CFPY (the minimum acceptable productivity for an anthurium genotype grown in the Caribbean) and all crosses except for 'Honduras/Local Mina Red' resulted in families with a proportion of the progenies with at least eight CFPY. The genetic study suggests that inheritance of productivity is polygenic and governed by both additive and non-additive genetic effects. Clonal breeding with recurrent selection strategies to harness both the additive and non-additive genetic effects should be instituted to accumulate genes for productivity. Special interventions such as progeny selection or line selection or markerassisted selection are needed to exploit the non-additive genetic effects. Horticulturally acceptable genotypes from these crosses have the ability to markedly increase the revenue of farmers. However, these genotypes have to be evaluated for other important traits such as disease resistance. Four crosses, 'Acropolis/Victoria', 'Honduras/Cross 3962', 'Local Orange/Cuba', and 'Pierrot/Local Orange', possessed progenies with productivities larger than the current most productive genotype, 'Kalapana'.

\section{Literature Cited}

Campbell, K.D. 2006. The effects of pruning and plant spacing on yield and horticultural characteristics in Anthurium andraeanum Hort. MPhil diss., Dept. Food Production, Univ. West Indies, St. Augustine, Trinidad.

Croat, T.B. 1988. Ecology and life forms of Araceae. Aroideana 11:4-55.

Dabholkar, A.R. 1999. Elements of biometrical genetics. Concept Publishing Company, New Delhi, India.

Dai, J. and R.E. Paull. 1990. The role of leaf development on anthurium flower growth. J. Amer. Soc. Hort. Sci. 115:901-905.

Dufour, L. and V. Guerin. 2003. Growth, developmental features and flower production of $\mathrm{An}$ thurium andraeanum Lind. Sci. Hort. 98:25-35.

Elibox, W. 2005. A study of the genetics of resistance to bacterial blight disease (C.A. Xanthomonas campestris pv. dieffenbachiae) and other horticultural characteristics in Anthurium andraeanum Hort. $\mathrm{PhD}$ diss., Univ. of the West Indies, St. Augustine, Trinidad and Tobago.

Elibox, W. and P. Umaharan. 2012. A study of morphophysiological descriptors of cultivated Anthurium andraeanum Hort. HortScience 47:1234-1240. 
Falconer, D.S. 1981. Introduction to quantitative genetics. Longman, London, UK.

Han, T.-H., H.J. van Eck, M.J. De Jeu, and E. Jacobsen. 2002. Mapping of quantitative trait loci involved in ornamental traits in Alstroemeria. HortScience 37:585-592.

Harding, J., T.G. Byrne, and R.L. Nelson. 1981. Estimation of heritability and response to selection for cut-flower yield in gerbera. Euphytica 30:313-322.

Henny, R.J., A.R. Chase, and L.S. Osborne. 1991. Anthurium production guide. Apopka Fol. Plant Res. Note RH-91-3.

Higaki, T., J.S. Lichty, and D. Moniz. 1994. Anthurium culture in Hawaii. HITAHR Res. Ext. Ser. 152.

Holder, A.W.B. 2005. A screening method for identifying resistance to bacterial leaf spot (C.A. Acidovorax anthurii) disease in Anthurium andraeanum Hort. MPhil diss., Univ. of the West Indies, St. Augustine, Trinidad and Tobago.
Kamemoto, H. and A.R. Kuehnle. 1996. Breeding anthuriums in Hawaii. Univ. Hawaii Press, Honolulu, HI.

Kamemoto, H., J. Kunisaki, M. Aragaki, and T. Higaki. 1986. Evaluation of anthurium accessions. HITAHR Res. Ext. Ser. 069.

Kamemoto, H. and H.Y. Nakasone. 1963. Evaluation and improvement of anthurium clones. Hawaii Agr. Exp. Sta. Tech. Bull. 58.

Kearsey, M.J. and H.S. Pooni. 1996. The genetical analysis of quantitative traits. Chapman and Hall, London, UK.

Kobayashi, K.D., A.F. Kawabata, and J.S. Lichty. 2006. Effects of photoselective shadecloths on potted Dracaena and Anthurium plants. HortScience 41:1053-1054.

Leon, A.J., M. Lee, and F.H. Andrade. 2001. Quantitative trait loci for growing degree days to flowering and photoperiod response in sunflower (Helianthus annuus L.). Theor. Appl. Genet. 102:497-503.
Lush, J.L. 1943. Animal breeding plans. Iowa State College Press, Ames, IA.

Mather, K. 1943. Polygenic inheritance and natural selection. Biol. Rev. Camb. Philos. Soc. 18:32-64.

Mohan, M., S. Nair, A. Bhagwat, T.G. Krishna, M. Yano, C.R. Bhatia, and T. Sasaki. 1997. Genome mapping, molecular markers and marker-assisted selection in crop plants. Mol. Breed. 3:87-103.

Nakasone, H.Y. and H. Kamemoto. 1962. Anthurium culture. Haw. Agric. Exp. Sta. Tech. Bull. 50.

NCSS. 2007. Number Crunching Statistical System. NCSS, Kaysville, UT.

Simmonds, N.W. 1979. Principles of crop improvement. Longman Inc., New York, NY.

van Herk, I.M., I.M. van Koppen, I.S. Smeding, I.C. van der Elzen, N. van Rosmalen, I.J. van Dijk, I.A. Lont, and I.J. van Spingelen. 1998. Cultivation guide anthurium. Anthura, Bleiswijk, The Netherlands. 